\title{
Two Challenges to the System of Periclase Quality Evaluation
}

\author{
L. M. Axelrod ${ }^{1}$, I. G. Maryasev ${ }^{1}$, A. A. Platonov ${ }^{1} \&$ D. R. Melnikova ${ }^{1}$ \\ ${ }^{1}$ Magnezit Group, Russia \\ Correspondence: I. G. Maryasev, Magnezit Group, Russia. E-mail: imaryasev@ magnezit.com
}

Received: June 11, 2015 Accepted: June 27, 2015 Online Published: October 9, 2015

doi:10.5539/jmsr.v5n1p12 URL: http://dx.doi.org/10.5539/jmsr.v5n1p12

\begin{abstract}
A new method of estimating the fused periclase quality - the revision of international standards. Quality and service life of refractories on the basis of fused periclase depend to a large extent upon the size of periclase crystals and its mineralogical composition. During fusion of periclase it is impossible to obtain completely homogeneous material with identical crystals size. That is why it is generally accepted to evaluate quality of fused periclase by the average crystals size. Measurements of this item are usually done with the help of generally adopted method of chords, which was developed in the last century and has a number of drawbacks. Magnezit Group developed a new objective method of digital analysis during microscopic examination of structural elements of fused periclase. It allows to considerably improve objectivity of obtained data. The main feature of the new method is application of the system of images analysis, which allows to carry out in automatic mode measurements on the preliminary created digital model of the whole area of the polished section. With the help of the digital model it is possible to calculate average size of fused periclase crystals taking into account number of crystals as well as percentage of the area occupied by them.

Does $\mathrm{CaO} / \mathrm{SiO}_{2}$ ratio influence service life of refractories? New view of old rules. Till today it was considered that one of the characteristics of fused periclase quality is coefficient of basicity $-\mathrm{CaO} / \mathrm{SiO}_{2}$, ratio, which should be more than 2. Magnezit Group carried out investigations of coarse-crystalline fused periclase with $\mathrm{MgO}>97.5 \%$ content and with various $\mathrm{CaO} / \mathrm{SiO}_{2}$ ratios. We present in this report the main study results: if the impurities content is low in the fused periclase with $\mathrm{MgO}>97.5 \%$, then coefficient of basicity exerts limited influence onto the service life of periclase-carbon bricks.
\end{abstract}

Keywords: Fused periclase, linear method of determination of crystals size, method of random chords, digital method of determination, periclase-carbon bricks, lining, $\mathrm{CaO} / \mathrm{SiO}_{2}$ ratio

\section{Introduction}

Quality of refractory materials, produced with application of fused and sintered periclase, depends upon a number of its characteristics. It was found out that the size of periclase crystals - in addition to its chemical composition, mineral composition of phases, located between crystals, apparent density - plays considerable role. As was proved on practice, the size of crystals exerts considerable influence upon wear resistance of bricks, produced with application of periclase, first of all of periclase - carbon refractories, which are widely used in steel making ((Riepl \& Barthel, 1991; Steinwender \& Bugajski, 1991; Mosser \& Riepl, 1988). Maximally exact evaluation of crystals size in quantitative analysis is necessary not only for selecting periclase of this or that quality for production of refractory materials, but also for control of technological factors during production of fused periclase.

Determination of chemical composition and bulk density are standardized while determination of crystal size is done with the help of various procedures, that is why precision of results, obtained in different laboratories, is often not identical (Riepl \& Barthel, 1991; Mosser \& Riepl, 1988). It is related both to the difficulty of selecting a representative sample for investigation and to discrepancies in applied methodologies. There is no universally accepted classification of fused periclase by crystals size.

It is known, that for the products of melt crystallization including periclase there is a logarithmic normal law of crystals diameters distribution (under the term "periclase crystal diameter" we understand average crystal size, i.e. average value between the length and the width of a crystal, analogously to the term "periclase crystal size")

Quantitative evaluation of crystals size distribution is related to obtaining and analysis of considerable statistical material, permitting to establish a distribution law (Sivash, Perepelitsin, \& Mityushov, 2001). 
There are a number of methods for quantitative assessment of periclase crystal size in metallographic sections on the basis of random sampling. As other quantitative methods they are based on presentation of limitlessly large number of intersections of grains with parallel planes or on overlaying onto images of calibrated nets of certain size. Theoretical basics of the methods are given in detail in (Saltykov, 1976). But stereometric methods (developed in the last century) for microscopic analysis of crystals require much time and are rather labour intensive. Quantitative assessments and calculations of microstructure elements on polished sections or metallographic sections were previously done visually by way of viewing directly into the microscope eyeglasses.

In the century of digital technologies, when spaceships are ploughing the space, the time has come to improve the quality of optical-microscopic measurements using modern digital equipment and programs of images analysis.

\section{Linear Method of Assessment}

Linear sizes were first measured in divisions of eyeglass scale. Then obtained results were multiplied for the division value. It was necessary to use during analysis various magnifications from $10 \times$ up to $500 \times$, as inadequate magnification in quantitative analysis often led to erroneous results in assessment of two-dimensional structure parameters as a consequence of detection of new small crystals (grains) under high magnification (Sivash, Perepelitsin, \& Mityushov, 2001). Technology of the most widely used «manual» linear method of crystal size evaluation by way of random chords consists of the following:

- Selection and preparation of a sample for investigation:

- visual evaluation of the total sample and classification of lumpy periclase by colour, structure, texture and cryslalline particles size; evaluation of share of each periclase class;

- preparation of sample for investigation. If periclase is in the form of large lumps, it is sawn along the chosen plane, finished and polished. Lumps of periclase less than $10 \mathrm{~mm}$ in size are preliminary coated with epoxy resin, then finished and polished;

- Methodology of microscopic investigation:

- adjustment of microscope for $100 \times$ magnification with the help of eyeglass.

- installation of polished sample into holder on microscope table. The first site in the periclase sample is chosen and image is focused.

- displacement of the sample to the edge of the line of one crystal from the edge of the net.

- determination of crystals size, crossing the line (Figure 1). If a crystal possesses isometrically rounded shape, then one of its middle diameter is measured. If the shape of a crystal is elongated, then its average size is determined, i.e. average value between the maximal length and width of the grain.

- after finishing analysis of a certain fragment the microscope table is displaced lower on the line parallel to the previously investigated site in order to measure another part of the sample and to repeat the process up to the end of the sample edge (Figure 2).

- for determination of average crystal size it is necessary to assess the size of not less than 250 crystals.

- for calculation of final average crystal size the following equation is used: $L_{a v}=s / n$, where $L_{a v}$-average crystal size (microns); $s$ - sum of crystals size (microns); $n$ - number of examined crystals (pcs.).

Methodology of grid application (ASTM Norm E 112-96/2004) and a number of other methods can be considered as more or less perfected variants of linear method. 




Figure 1. Evaluation of dimensions of separate periclase crystals, found out in the field of microscope objective by method of overlapping lines (chords). In reflected light. Magnification: 25x. Plane lines 1 and 2 were chosen for measurements
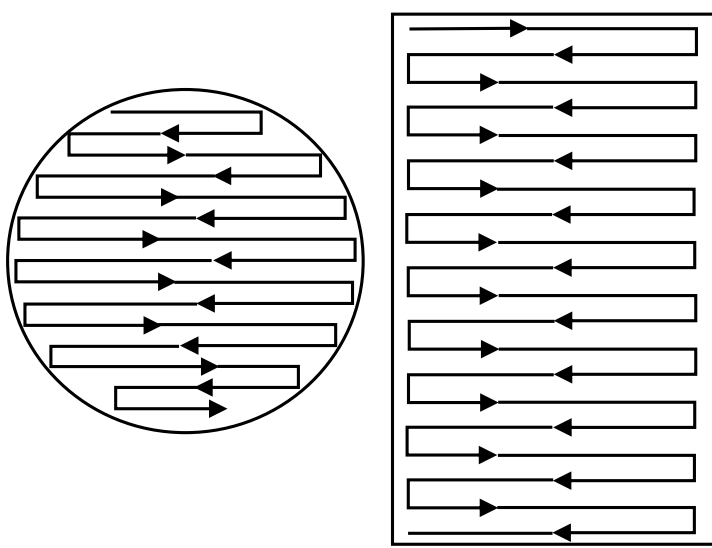

Figure 2. Schemes of moving of sample during measurement of crystals size of periclase by line method

\section{Digital Method of Crystals Assessment}

Modern methods of microscopic investigation allow to obtain more reliable and exact results in shorter time. At Magnezit Group equipping of the existing optical microscope Axioplan with the system of digital analysis allowed to modify and to supplement methods of determination of microscopic parameters of refractory materials and raw materials. The essence of the suggested method consists in modeling of a digital image of a large area of polished section 1200-1500 $\mathrm{mm}^{2}$ under any necessary magnification, embracing its whole surface Figure 3).

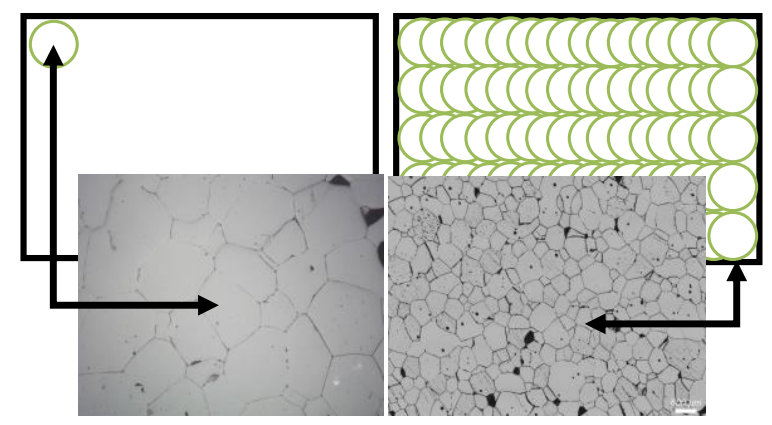

Figure 3. Scheme of image capture single (left) and crosslinked (right) 
After formation of an image is finished, evaluation of geometric parameters of two-dimensional structure is done with the help of special software, in particular of the software Image-Pro Premier by the company Media Cybernetics (Figure 4).

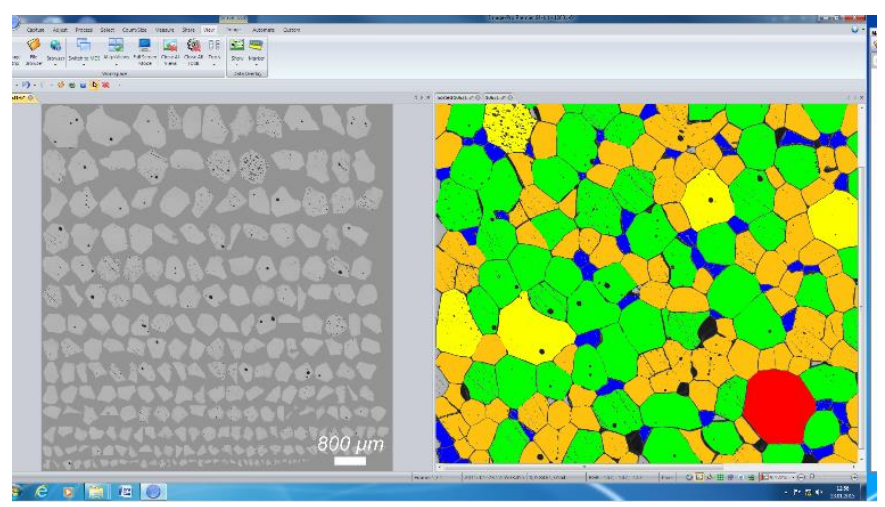

Figure 4. Example of automatic crystal size distribution

Zonal formation of crystals of different sizes occurs during melting of a block of fused periclase from a few microns to several centimeters. During crushing pieces of periclase crystals with different sizes (from different zones) are mixed. It becomes necessary to get an objective picture about crystals size and get the average data. With the help of image analysis system it is possible to carry out automatic measurements of material of any grain composition.

During investigation of fused periclase we obtain distinct notion about crystals shape in typical polished sections and determine size and area of all the crystals, which are found in the image (Figure 5a and 5b).

When the borders of crystals are poorly distinguishable it is necessary to etch the surface of the polished section in acid. A typical number of measured crystals for fused periclase is from 600 to 1200 depending upon crystals size.

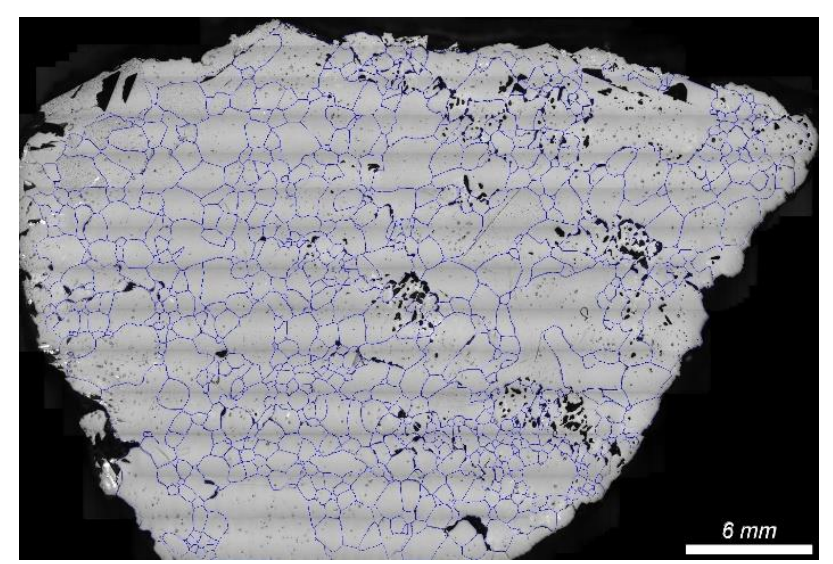

Figure 5a. Example of evaluation of periclase crystal area over the whole surface of the polished section. In reflected light. Magnification: $4 \times$ 


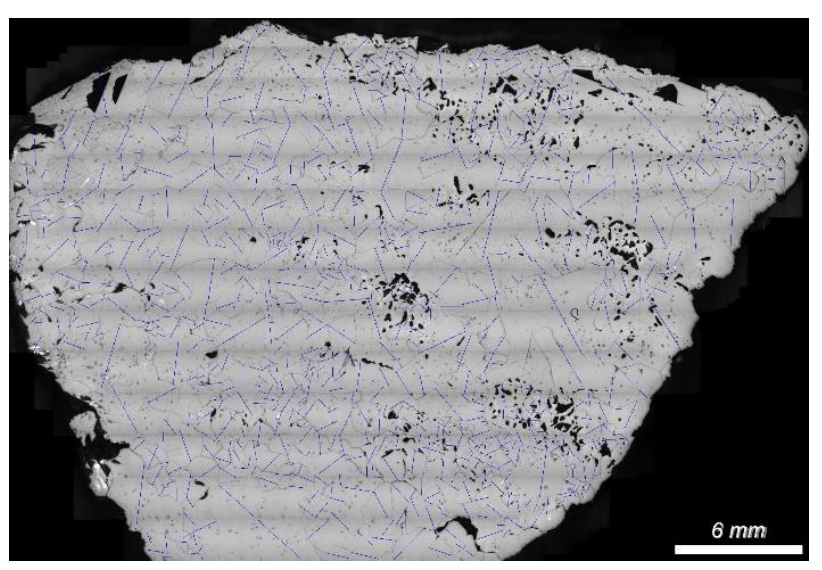

Figure 5b. Example of evaluation of periclase crystals average size over the whole surface of the polished section. In reflected light. Magnification: $4 \times$

After measurements are finished, statistical treatment of data takes place and the maximal, minimal and average crystal size are determined, as well as graphs of sizes distribution are drawn with evaluation of parameters $\mathrm{L}_{10}, \mathrm{~L}_{50}$ and $\mathrm{L}_{90}$ (subscripts mean crystal size corresponding to 10,50 and $90 \%$ share of crystals, which are smaller than a certain diameter).

Often fused periclase has different crystalline structure with areas, where aggregation of small crystals is observed. These small crystals occupy in the total volume of the sample a small share, but nevertheless, exert strong influence onto the parameter of average crystal size based on the total number of crystals (Figure 6).

That is why it is reasonable to determine and compare average area crystal size (La average), which takes into account the share of the area occupied by crystals. It is calculated by the formula:

where $\mathrm{Ai}$ - area of crystal, $\mathrm{Li}$ - average crystal size.

$$
\mathrm{La}_{\mathrm{av}} \text {. equals }=\sum(\mathrm{Ai} \times \mathrm{Li}) / \sum \mathrm{Ai},
$$

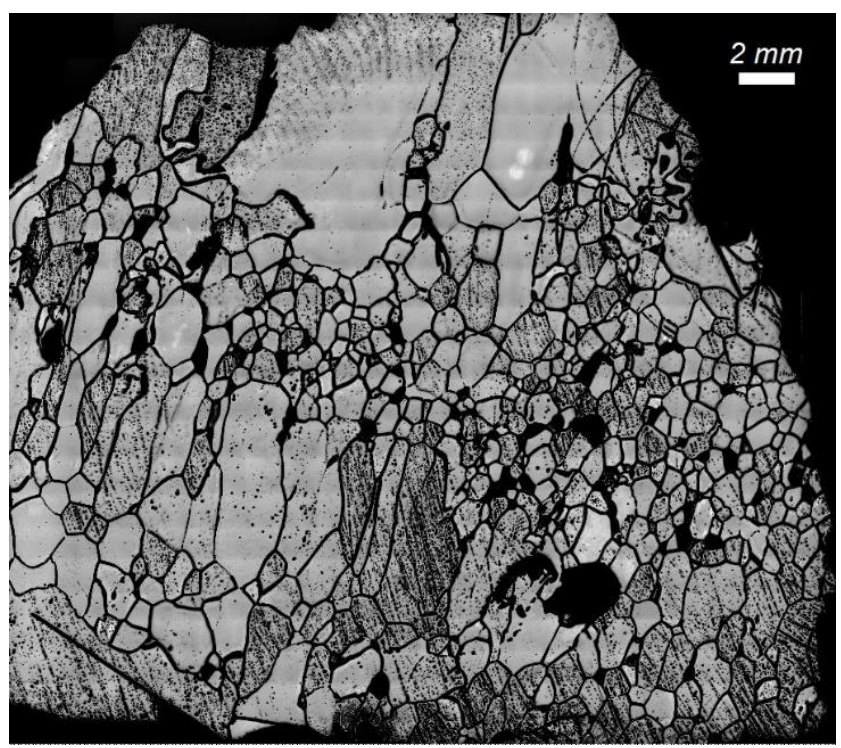

Figure 6. Fused periclase with areas of different crystalline structure

For comparison we presented in Table 1 and on Figure $7 \mathrm{a}, 7 \mathrm{~b}$ data on the character of crystal size distribution in fused periclase, produced by Magnezit Group. The size was determined by two methods: the «old» one and the «new» one. 
Table 1. Example of parameters values, characterizing size of fused periclase crystals

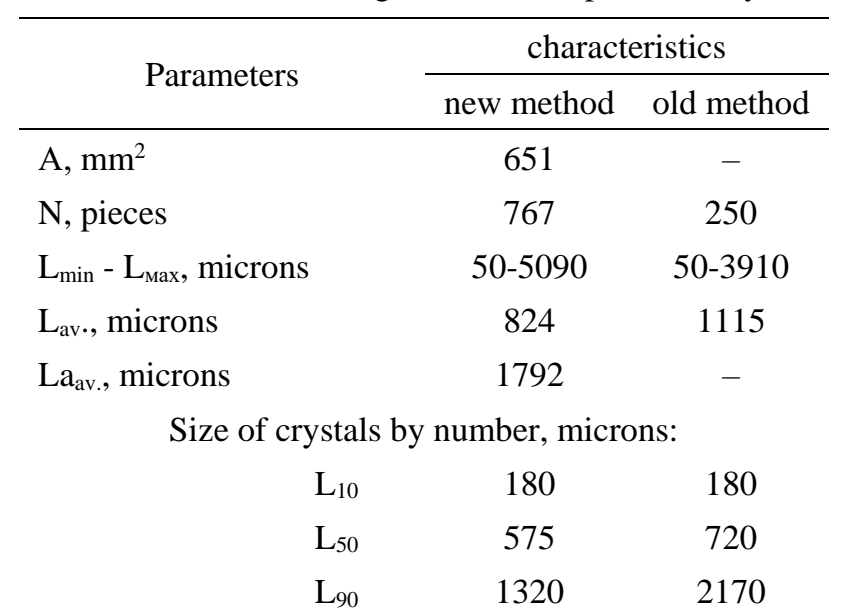

Size of crystals by area, microns:

$\begin{array}{lcc}\mathrm{La}_{10} & 560 & - \\ \mathrm{La}_{50} & 1400 & - \\ \mathrm{La}_{90} & 3270 & -\end{array}$

Mass fraction of crystals by number, $\%$

$\begin{array}{lll}\mathrm{M}_{500} & 57 & 65 \\ \mathrm{M}_{1000} & 22 & 37\end{array}$

Mass fraction of crystals by area, $\%$

\begin{tabular}{ccc}
$\mathrm{Ma}_{500}$ & 93 & - \\
$\mathrm{Ma}_{1000}$ & 67 & - \\
\hline
\end{tabular}

$\mathrm{A}-$ area of surface of the polished section, $\mathrm{mm}^{2}$

$\mathrm{N}$ - total number of crystals in the polished section, pcs.

$\mathrm{L}_{\min }-\mathrm{L}_{\mathrm{Max}}-$ minimal and maximal size of periclase crystals in the polished section, microns.

$\mathrm{L}_{\mathrm{av} .}$ - arithmetic mean value by parameter of average crystal size, microns.

$\mathrm{La}_{\mathrm{av} .}$ - average area of crystal size, microns.

$\mathrm{L}_{10}-10 \%$ of crystals smaller in size than the size in question;

$\mathrm{L}_{50}-50 \%$ of crystals of the size in question;

$\mathrm{L}_{90}-90 \%$ of crystals smaller in size than the size in question.

$\mathrm{La}_{10}-10 \%$ of the area of the polished section consist of crystals smaller in size than the size in question;

Las0 $-50 \%$ of the area of the polished section consist of crystals of the size in question;

$\mathrm{La}_{90}-90 \%$. of the area of the polished section consist of crystals smaller in size than the size in question.

$\mathrm{M}_{500}$ and $\mathrm{M}_{1000}$ - share of crystals in \% larger than 500 microns and 1000 microns depending upon the number of crystals.

Ma500 and Ma1000 - percentage of crystals larger than 500 microns and 1000 microns depending upon the area occupied by them.

500 microns and 1000 microns depending upon the area occupied by them. 

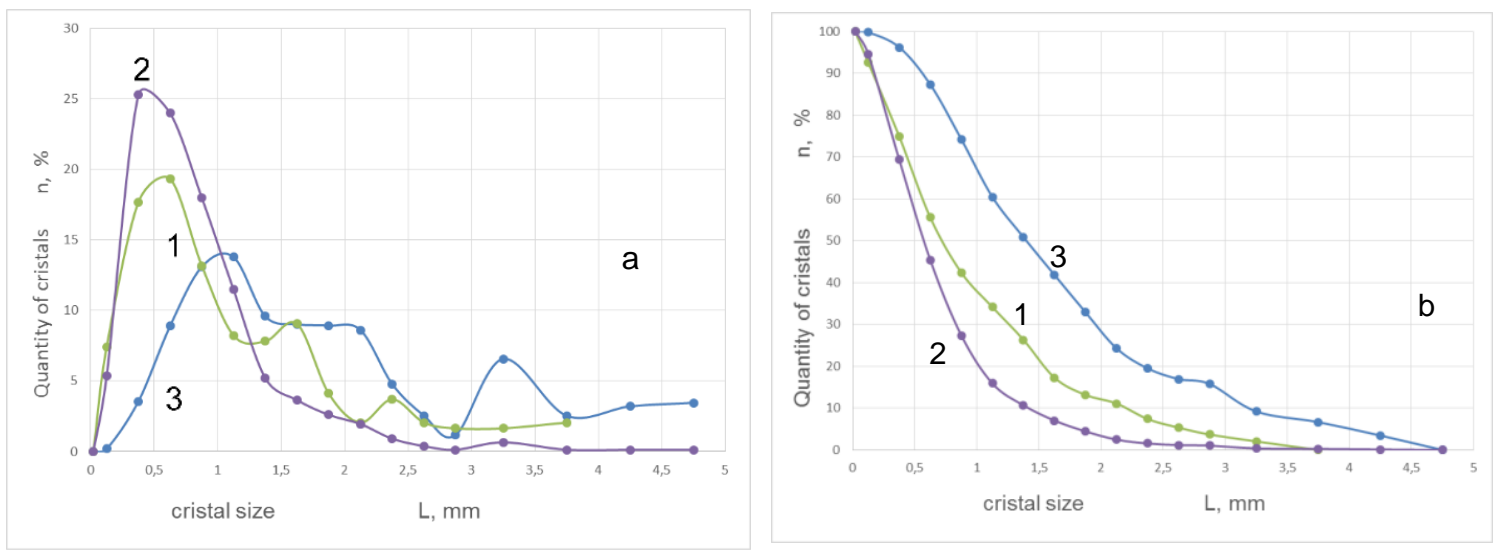

Figure 7. Curves of crystal size distribution in fused periclase

$\mathrm{a}$ - differential curve of crystal size distribution, $\mathrm{b}$ - integral curve of crystal size distribution.

1 - old method of chords, 2 - new method of global analysis; distribution by number of crystals.

3 - new method of global analysis; distribution by area of crystals.

From the Table 1 we can see, that method of microscopic analysis with the help of chords (the old method) gives overstated values of crystals size (especially by the item $\mathrm{L}_{90}$ ), which differ from the real size of all the crystals. Positive results after introduction of the new method consist in the following:

- visualization of obtained results;

- possibility of control and repeated checks;

- $\quad$ organization of electronic data bases and accumulation of statistics;

- $\quad$ possibility to do on one and the same image measurements of not only crystals size, but of any basic geometric parameters of plane structure, such as, for example, surface of a separate particle and total surface of contacts, diameter of a spherical particle, dihedral angle between facets, number of microparticles in a unit of volume, number of contacts and other;

- measurements of crystals size directly on one and the same image allow to obtain precise data on size of very large crystals, which don't fit entirely in the microscope eyeglass field. Previously it was necessary to move the microscope table several times during measurement of such crystals. Now there appeared possibility to obtain precise data on the elements with absolutely different linear sizes, while previously it was necessary in such a case to change microscope magnification during measurements of small crystals;

- reliability and objectivity of obtained results increased. Good repeatability of data is ensured and influence of human factor is lowered. Such results are achieved thanks to increase of amount of data retrieval as well as thanks to retention in real time of all the measurement results. It is possible to assess the obtained result at any moment and if necessary to introduce corrections into determined structure parameters.

All the grades of tested fused periclase are standard products, manufactured by Magnezit Group. They were studied with the help of the new method of crystals size determination. Mineral and chemical compositions were studied as well. Obtained results for some of grades, which are part of the new product line Russian Magnezit ${ }^{\text {TM }}$, are presented in Table 2.

New product line Russian Magnezit ${ }^{\mathrm{TM}}$ consists of fused periclase and dead-burned clinker grades with $\mathrm{MgO}$ content not less than $97 \%$, manufactured in Russia on the basis of magnesite from Siberian deposits. We tried to suggest a number of indicators, which in our opinion, describe in fullest measure distribution of fused periclase crystals by size.

Often fused periclase has different crystalline structure with areas, where aggregation of small crystals is observed, These small crystals occupy in the total volume of the sample a small share, but nevertheless, exert strong influence onto the parameter of average crystal size based on the total number of crystals. That is why it is feasible to determine and compare average area crystal size, which takes into account the share of area occupied by crystals. 
Obtained results for some of grades are presented in Table 2. We have developed techniques, allowing to change within certain limits average size of crystals and, accordingly, average areal size and area of the whole number of crystals by way of changing fusion mode parameters during production of fused periclase of one and the same composition.

Table 2. Characteristics of different grades of fused periclase, which are part of Magnezit Group's product line Russian Magnezit ${ }^{\mathrm{TM}} \cdot \rho$ - bulk density, $\mathrm{g} / \mathrm{cm}^{3}$

\begin{tabular}{|c|c|c|c|c|c|c|}
\hline \multicolumn{2}{|c|}{ Parameters } & Imported & DTMF & DTMF & DTMF & DTMF \\
\hline \multirow{2}{*}{\multicolumn{2}{|c|}{$\mathrm{L}_{\mathrm{av} .}$, microns }} & & & & & \\
\hline & & 768 & 869 & 1077 & 901 & 801 \\
\hline \multicolumn{2}{|c|}{$\mathrm{La}_{\mathrm{av} .}$, microns } & 3288 & 3458 & 2779 & 2137 & 2168 \\
\hline \multicolumn{2}{|c|}{$\mathrm{L}_{\min }-\mathrm{L}_{\text {Max }}$, microns } & $48-8200$ & $80-10200$ & $70-7150$ & $110-7360$ & $60-5280$ \\
\hline $\mathrm{L}_{10}$ & $\mu \mathrm{m}$ & 160 & 180 & 200 & 240 & 170 \\
\hline $\mathrm{L}_{50}$ & $\mu \mathrm{m}$ & 550 & 560 & 900 & 700 & 550 \\
\hline $\mathrm{L}_{90}$ & $\mu \mathrm{m}$ & 1450 & 1300 & 1750 & 1340 & 1120 \\
\hline $\mathrm{La}_{10}$ & $\mu \mathrm{m}$ & 910 & 620 & 900 & 640 & 540 \\
\hline $\mathrm{La}_{50}$ & $\mu \mathrm{m}$ & 2340 & 2650 & 1910 & 2240 & 2520 \\
\hline $\mathrm{La}_{90}$ & $\mu \mathrm{m}$ & 5620 & 6100 & 5150 & 5140 & 5320 \\
\hline $\mathrm{M}_{500}$ & $\%$ & 72 & 60 & 73 & 70 & 55 \\
\hline $\mathrm{M}_{1000}$ & $\%$ & 32 & 17 & 35 & 25 & 14 \\
\hline $\mathrm{Ma}_{500}$ & $\%$ & 94 & 98 & 97 & 95 & 93 \\
\hline $\mathrm{M}_{\mathrm{a} 1000}$ & $\%$ & 72 & 75 & 83 & 67 & 62 \\
\hline \multicolumn{7}{|c|}{ Mineral composition, \% (volume fraction): } \\
\hline \multicolumn{2}{|c|}{ periclase $\mathrm{MgO}$} & $97-98$ & $97-98$ & $97-98$ & $97-98$ & $>98$ \\
\hline \multicolumn{2}{|c|}{ Monticellite $\mathrm{CaMgSiO}_{4}$} & - & - & - & $1-2$ & - \\
\hline \multicolumn{2}{|c|}{ Mervenite $\mathrm{Ca}_{3} \mathrm{Mg}\left(\mathrm{SiO}_{4}\right)_{2}$} & $\leq 1$ & $\leq 1$ & $<1$ & $1-2$ & $\leq 1$ \\
\hline \multicolumn{2}{|c|}{ Belite $\mathrm{Ca}_{2} \mathrm{SiO}_{4}$} & $1-2$ & $2-3$ & $1-2$ & - & $1-2$ \\
\hline \multicolumn{7}{|c|}{ Chemical composition, \% (mass fractions): } \\
\hline \multicolumn{2}{|c|}{$\mathrm{MgO}$} & 98,26 & 97,44 & 98,09 & 97,90 & 98,66 \\
\hline \multicolumn{2}{|c|}{$\mathrm{Al}_{2} \mathrm{O}_{3}$} & 0,05 & 0,11 & 0,17 & 0,15 & 0,13 \\
\hline \multicolumn{2}{|c|}{$\mathrm{SiO}_{2}$} & 0,42 & 0,60 & 0,44 & 0,66 & 0,34 \\
\hline \multicolumn{2}{|c|}{$\mathrm{CaO}$} & 0,89 & 1,45 & 1,07 & 1.02 & 0,72 \\
\hline \multicolumn{2}{|c|}{$\mathrm{Fe}_{2} \mathrm{O}_{3}$} & 0,38 & 0,41 & 0,24 & 0,27 & 0,12 \\
\hline \multicolumn{2}{|c|}{ sum, $\sum$} & 100,0 & 100,00 & 100,00 & 100,00 & 100,00 \\
\hline \multicolumn{2}{|c|}{$\mathrm{CaO} / \mathrm{SiO}_{2}$} & 2,12 & 2,60 & 2,43 & 1,55 & 2,12 \\
\hline \multicolumn{2}{|c|}{$\rho, \mathrm{g} / \mathrm{cm}^{3}$} & 3,52 & 3,48 & 3,52 & 3,51 & 3,52 \\
\hline
\end{tabular}

\section{Evaluation of influence of $\mathrm{CaO} / \mathrm{SiO}_{2}$ ratio}

With the aim of evaluation of influence of fused periclase quality with various $\mathrm{CaO}$ and $\mathrm{SiO}_{2}$ ratio we tested fused periclase of DTMF 98 grade, which is a part of the new product line Russian Magnezit ${ }^{\mathrm{TM}}$, produced by Magnezit Group (97,6-98,1\% $\mathrm{MgO}, \mathrm{CaO} / \mathrm{SiO}_{2} 1,4-1,6$, bulk density 3,48-3,52 $\mathrm{g} / \mathrm{cm}^{3}$ ) and imported fused periclase of FM 98CS grade (more than $97,7 \% \mathrm{MgO}, \mathrm{CaO} / \mathrm{SiO}_{2} \geq 2,2$, apparent density $3,48-3,52 \mathrm{~g} / \mathrm{cm}^{3}$ ) which are used as main components in production of periclase-carbon refractories for slag line of 130-tons steel-teeming ladles.

Monticellite $\left(t_{\mathrm{m}}=1500{ }^{\circ} \mathrm{C}\right)$ and mervenite $\left(t_{\mathrm{m}}=1575^{\circ} \mathrm{C}\right)$ are present as intergranular phase in periclase of DTMF 98 grade in the form of layers 10-20 microns thick (Figure 8).

A part of monticellite and mervenite are distributed in crystals of periclase. Belite $\left(t_{\mathrm{m}}=2130{ }^{\circ} \mathrm{C}\right)$ prevails in the imported periclase of FM 98CS grade (Figure 9). Mervenite (see Table 2) is in subordinate amount. 
Periclase-carbon bricks have the following composition: basis - fused periclase of fraction 0-6 $\mathrm{mm}, 9 \pm 1 \%$ of graphite, antioxidant - metallic Al, Carbores $\mathrm{P}$ and phenol-formaldehyde binder. Physical and chemical properties of bricks are identical both after thermal treatment and after coking (see Table 3).

Table 3. Physico-mechanical parameters of periclase-carbon bricks after and before coking

\begin{tabular}{|c|c|c|c|}
\hline \multirow{2}{*}{\multicolumn{2}{|c|}{ Physical and mechanical properties }} & \multicolumn{2}{|c|}{ PC-bricks on the basis of fused periclas } \\
\hline & & DTMF 98 & FM 98 CS \\
\hline \multicolumn{2}{|l|}{ Ration $\mathrm{CaO} / \mathrm{SiO}_{2}$} & 1.55 & 2.12 \\
\hline Apparent & before coking & 3,8 & 3,5 \\
\hline $\begin{array}{c}\text { (open) porosity, } \\
\Pi, \%\end{array}$ & after coking & 9,6 & 8,4 \\
\hline Bulk density, & before coking & 3,05 & 3,07 \\
\hline$\rho, \mathrm{g} / \mathrm{CM}^{3}$ & after coking & 3,00 & 3,02 \\
\hline Ultimate compressive strength, & before coking & 42,8 & 50,4 \\
\hline$\delta, \mathrm{N} / \mathrm{mm}^{2}$ & after coking & 35,4 & 45,6 \\
\hline
\end{tabular}

Bricks made from imported periclase of FM 98CS grade and from domestic DTMF 98 grade were tested at a number of plants in slag line of different vessels. Operating conditions were approximately the same. Share of vacuumized metal which influences corrosion resistance of bricks in slag line was also approximately the same at all the plants.

At the plant №1 with EAF-130 and at the plant №2 with EAF-150, steel teeming ladles operate in the cycle: ladle-furnace (100\% of heats) - vacuum degasser RH (50-60\% of heats) - casting at continuous casting machine (CCM); at the plant №3 with EAF-150 the ladles operate in the following cycle: ladle-furnace (100\% of heats) vacuum degasser VD/VOD (50-60\% of heats). Basicity of slag $\left(\mathrm{CaO}+\mathrm{MgO} / \mathrm{SiO}_{2}+\mathrm{Al}_{2} \mathrm{O}_{3}\right)$ is in the range of 1,9-2,4.

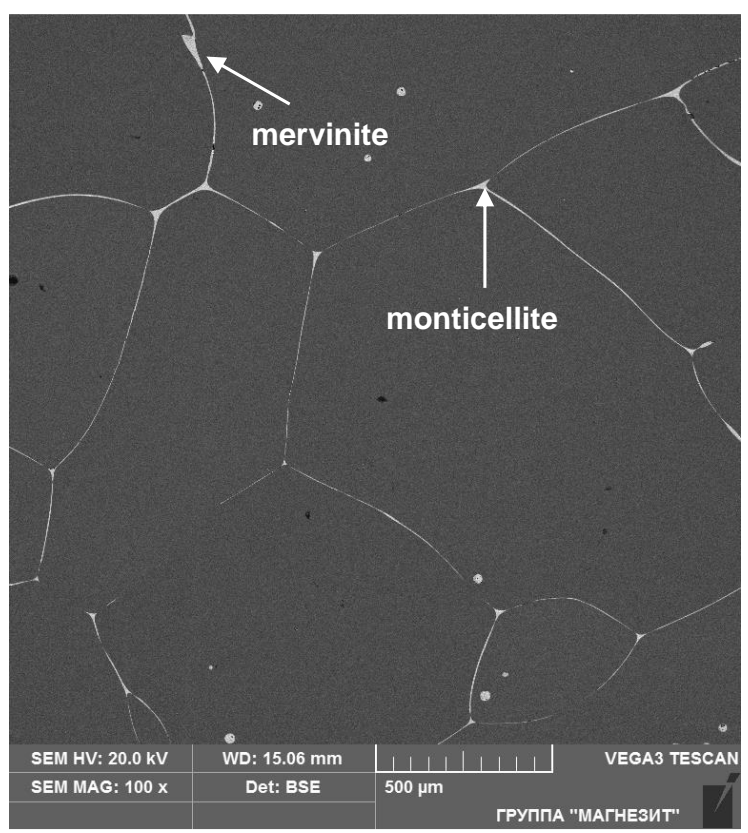

Figure 8. Microstructure of the sample of fused periclase of DTMF 98 grade. SEM. Detector BSE. Magnification: $100 \times$



Figure 9. Microstructure of the sample of fused periclase of FM 98CS grade. SEM. Detector BSE.

Magnification: $100 \times$ 
At the plant №1 (EAF-130) service life of the slag line of steel teeming ladle amounted averagely to 40 heats, no matter what grade of fused periclase was used in composition of periclase-carbon bricks.

At the plant №2 (EAF-150) they use technology of hot repair of some areas of steel ladle slag line. Final service life is 110 heats and consumption of periclase-carbon bricks (on the basis of DTMF 98 grade periclase) for repair after one campaign amounted to 4,5 tons, instead of 8,7 tons when bricks made of imported periclase FM 98CS were used. And it should be pointed out that repair works were begun 10-12 heats later.

At the plant №3 service life of bricks in the slag line of steel teeming ladle (before substitution of bricks) amounted to $43-45$ heats in both cases.

At the plant №4, where alloyed corrosion resistant steel is produced, melting is done in EAF-120 and then metal is treated in the vessel ASEA or in the degasser VD/VOD. In severe conditions of aggressive action of slag during treatment of metal in the ladle for up to three hours service life of slag lines made of bricks with periclase of DTMF 98 grade achieves averagely 37 heats, while service life of bricks with periclase of FM 98CS grade amounted averagely to 34 heats.

Resistance of slag lines of ladles lined periclase-carbon bricks based on different periclase were approximately the same. Parameters of thermal vessels, operation conditions and service life are shown in Table 4.

Table 4. Parameters of thermal vessels, operation conditions and service life

\begin{tabular}{|c|c|c|c|c|c|}
\hline \multirow{2}{*}{\multicolumn{2}{|c|}{ Technical characteristics and parameters }} & \multicolumn{4}{|c|}{ Steel ladles of the companies } \\
\hline & & \multirow{2}{*}{$\begin{array}{l}\text { № } 1 \\
130\end{array}$} & \multirow{2}{*}{$\begin{array}{c}\text { № } 2 \\
150\end{array}$} & \multirow{2}{*}{$\begin{array}{r}\text { № } 3 \\
150\end{array}$} & \multirow{2}{*}{$\begin{array}{c}\text { № } 4 \\
120\end{array}$} \\
\hline Steelmaking unit EAF & & & & & \\
\hline $\begin{array}{l}\text { The proportion of metal processed in the } \\
\text { unit ladle furnace, } \%\end{array}$ & & 100 & 100 & 100 & - \\
\hline \multirow{3}{*}{ Vacuumizing of metal, $\%$} & Unit RH & $50-60$ & $50-60$ & - & - \\
\hline & VD/VOD, ASEA & - & - & $50-60$ & 100 \\
\hline & Processing time, $\min$ & $18-25$ & $18-30$ & $18-30$ & $150-180$ \\
\hline $\begin{array}{l}\text { Basicity of the slag } \\
(\mathrm{CaO}+\mathrm{MgO}) /\left(\mathrm{SiO}_{2}+\mathrm{Al}_{2} \mathrm{O}_{3}\right)\end{array}$ & & 2,4 & 2,0 & 2,1 & $1,7-2,3$ \\
\hline \multirow{2}{*}{$\begin{array}{l}\text { Resistance of PC-bricks } \\
\text { in slag line, number of heats }\end{array}$} & with DTMF 98 & $>40$ & $\geq 110$ & $43-45$ & av. 37 \\
\hline & with FM 98 CS & $>38$ & $\geq 110$ & $43-45$ & av. 34 \\
\hline Residual thickness of refractory & $\%$ & $25-35$ & $30-40$ & $30-40$ & $30-40$ \\
\hline
\end{tabular}

Process of periclase-carbon lining wear in metallurgical vessels takes place according to the well known scheme:

- oxidation of carbon component of the refractory with enlargement of pores. Appearance of large remified pores connected with each other. Oxidizing and reduction processes taking place inside refractory also add their share as well as processes providing for removal of gaseous products from reaction zone of the refractory (from the pores of the refractory) during out-of-furnace treatment of metal in the ladle;

- slag goes along formed pores - channels, in which there is no carbon, and comes into contact with coarse gariend periclase and with fine particles;

- grains of periclase are subjected to corrosion along the surface of contact with formation of secondary silicates, spinellides and others. At the same time washing out of grains from the structure takes place. It is confirmed by presence of periclase grains in the slag contacting the working surface of periclase-carbon refractory (Figure 10). 




Figure 10. Microstructure of the working zone of a sample of periclase - carbon brick after service. SEM. Detector BSE. Magnification: 293×. Washing out of grains of fused periclase from the refractory with formation of new phases - silicates, Al-Mg spinel (AMS) and complex spinelids

One can suppose, that the final stage of refractories wear has mechanical character and the speed of washing out of periclase grains from the oxidized refractory prevails over the process of slag interaction with the components in intercrystalline space. This version has been checked by comparison of periclase-carbon bricks made of fused periclase of different quality after service in slag lines.

In case of application of fused periclase and content of low-melt monticellite and mervinite totaling to $2,5 \%$ we have not discovered considerable influence onto the process of interaction of metallurgical slag (of basic composition) with periclase-carbon refractories in comparison with the case, when more high-melting belite occurs in intercrystalline space of periclase. The share of silicates in periclase DTMF 98 grade is so small that there is no continuous layer of silicates between crystals along which interaction with the slag may be possible, and in this case their quality isn't so important.

In the case of increasing share of silicates (from 2.5 to 4.0 percent) interlayer between the crystals become thicker and at them begins erosion, destruction grains (Figure 11).



Figure 11. Microstructure of the working zone of a sample of periclase - carbon brick after service. SEM. Detector BSE. Magnification: 35x. Erosion, destruction grains of fused periclase 
Identical result was obtained on EAFs at two plants. When carbon containing refractories on the basis of coarse-crystalline fused periclase of grades DTMF 98 and FM 98CS were used, service life of bricks in slag lines was found out to be equal: on the level of 800 heats.

At present periclase-carbon refractories for steel-teeming ladles and electric arc furnaces are manufactured at Magnezit Group with application of own coarse crystalline periclase. $\mathrm{CaO} / \mathrm{SiO}_{2}$ ratio in fused periclase with $\mathrm{MgO}$ content $97,5 \%$ and more is predetermined, but it has no decisive influence.

We are of the opinion that much greater influence onto the service life is exerted by such a characteristic as average size of periclase crystals and average areal size of crystals. Critical values of these items are correspondingly on the level of 300-500 microns and 1200-1500 microns. The larger is the size of periclase crystals, the higher is service life thanks to lowering the speed of the process of mechanical washout of decarbonized area.

In the case, considered in our report, difference between the average and average areal size of crystals of fused periclase of grades DTMF 98 and FM 98CS didn't influence service life of refractories as these characteristics were higher than 500 microns and 2000 microns correspondingly.

\section{Conclusions}

We are of the opinion that it is time to develop general universal requirements for determination of periclase crystal size and other characteristics of its quality with the help of novel equipment and software with the aim of development in the future of generally accepted methods and classification of fused periclase by size of crystals and standardization of measurements.

\section{References}

Riepl, K., \& Barthel, H. (1991). Large-crystal magnesia clinker for advanced refractories, an update and overview. UNITECR (pp. 97-101).

Mosser, J., \& Riepl, K. (1988). Method of determining the periclase crystal size of sintered magnesia. cfi/Ber (pp. 212-216).

Steinwender, W., \& Bugajski, J. (1991). Periclas Cristal Size - Importance, Determination, Propagation. UNITECR (pp. 91-97).

Sivash, V. G., Perepelitsin, V. A., \& Mityushov, N. A. (2001). Fused Periclase. Yekaterinburg: Urals' Worker (p. 578).

Saltykov, S. A. (1976). Stereometric Metallography. M.: Metallurgy (p.270).

\section{Copyrights}

Copyright for this article is retained by the author(s), with first publication rights granted to the journal.

This is an open-access article distributed under the terms and conditions of the Creative Commons Attribution license (http://creativecommons.org/licenses/by/3.0/). 